\title{
LED-FISH: Fluorescence microscopy based on light emitting diodes for the molecular analysis of Her-2/neu oncogene amplification
} Dagmar S Lang ${ }^{1}$, Tobias Zeiser ${ }^{2}$, Holger Schultz ${ }^{1}$, Florian Stellmacher ${ }^{1}$,
Ekkehard Vollmer ${ }^{1}$, Peter Zabel ${ }^{1,3}$ and Torsten Goldmann*1

Address: ${ }^{1}$ Clinical and Experimental Pathology, Research Center Borstel, Parkallee 3, D-23845 Borstel, Germany, ${ }^{2}$ Paracelsus Klinik HenstedtUlzburg, Department of Gynecology and Obstetrics, Schützenstrasse 55, D-23843 Bad Oldesloe, Germany and ${ }^{3}$ Medical University Hospitall III Lübeck/Medical Clinic, Research Center Borstel, Parkallee 35, D-23845 Borstel, Germany/Ratzeburger Allee 160, D-23562 Lübeck, Germany

Email: Dagmar S Lang - dlang@fz-borstel.de; Tobias Zeiser - dr.tobias.zeiser@pk-mx.de; Holger Schultz - hschultz@fz-borstel.de; Florian Stellmacher - fstellmacher@fz-borstel.de; Ekkehard Vollmer - evollmer@fz-borstel.de; Peter Zabel - pzabel@fz-borstel.de; Torsten Goldmann* - tgoldmann@fz-borstel.de

* Corresponding author

Published: 16 December 2008

Diagnostic Pathology 2008, 3:49
Received: 25 November 2008

Accepted: 16 December 2008

This article is available from: http://www.diagnosticpathology.org/content/3/1/49

(C) 2008 Lang et al; licensee BioMed Central Ltd.

This is an Open Access article distributed under the terms of the Creative Commons Attribution License (http://creativecommons.org/licenses/by/2.0), which permits unrestricted use, distribution, and reproduction in any medium, provided the original work is properly cited.

\begin{abstract}
Light emitting diodes (LED), which are available as small monochromatic light sources with characteristic features such as maximum illumination power combined with minimum energy consumption and extremely long lifespan have already proved as a highly potential low-cost alternative for specific diagnostic applications in clinical medicine such as tuberculosis fluorescence microscopy. Likewise, the most reliable evaluation of Her-2/neu (c-erbB2) gene amplification, which has been established in the last few years for routine diagnosis in clinical pathology as determinant towards Herceptin-based treatment of patients with breast cancer, is based on fluorescence in situ hybridization (FISH) and corresponding high priced fluorescence equipment. In order to test the possibility to utilize the advantages of low-cost LED technology on FISH analysis of c-erbB2 gene expression for routine diagnostic purposes, the applicability of a standard bright field Carl Zeiss Axiostar Plus microscope equipped with a Fraen AFTER* LED Fluorescence Microscope Kit for the detection of Her-2/neu gene signals was compared to an advanced Nikon Eclipse 80i fluorescence microscope in combination with a conventional $100 \mathrm{~W}$ mercury vapor lamp. Both microscopes were fitted with the same Quicam FAST CCD digital camera to unequivocally compare the quality of the captured images. C-erbB2 gene expression was analyzed in 30 different human tissue samples of primary invasive breast cancer, following formalin fixation and subsequent paraffin-embedding. The Her2/neu gene signals (green) were identifiable in the tumor cells in all cases and images of equal quality were captured under almost identical conditions by $480 \mathrm{~nm}$ (blue) LED module equipped standard Axiostar microscope as compared to conventional fluorescence microscopy. In this first attempt, these monochromatic LED elements proved in principle to be suitable for the detection of Her-2/neu gene expression by FISH. Thus, our own experiences emphasize the high potential of this technology to provide a serious alternative to conventional fluorescence microscopy in routine pathology; representing a sustainable technological progress, this low-cost technology will clearly give direction also to the growing field of molecular pathology.
\end{abstract}

* AFTER = Amplified Fluorescence by transmitted Excitation of Radiation 


\section{Findings}

Light Emitting Diodes (LED) are characterized by low cost, effective energy consumption and extremely long lifespan when compared to conventional light sources [1]. Both the small size and the lack of heat development by LED elements also contribute to these major advantages above conventional lighting technology that altogether imply considerable economic cost reductions. As a consequence, there has been a fast propagation of LED elements as important constituents in many different branches such as automobile industry, household or camping $[2,3]$. More recently, the availability of a variety of small monochromatic LED modules efficiently emitting the spectrum in a single desired bandwidth has stimulated the interest of clinical researchers to utilize this low-cost technology for advanced fluorescence microscopy in diagnostic research [4]. Since LED based light sources operate without increasing their temperature, common safety problems related to considerable heat production by conventional high pressure mercury lamps are completely avoided. Most recently, LED modules attached to standard light microscopes have been successfully applied in fluorescence-based screening of tuberculosis, pointing to the considerable reduction of related costs combined with increased safety and, as a consequence, to the potential for low-income countries to perform such advanced diagnostics of this disease in the near future [5,6]. Likewise, the increasing application of highly sensitive but also expensive molecular methods in clinical pathology such as the analysis of altered gene expression patterns for cancer diagnosis, has led to a general demand for reducing costs in routine processes. In the last few years, the evaluation of Her-2/neu status has considerably gained clinical importance related to the selection of patients with breast cancer, who will benefit most from a novel targeted therapy based on Herceptin, a humanized monoclonal antibody directed against this protein $[7,8]$. Thus, overexpression of Her-2/neu protein represents one of only few available predictive markers for an individualized and more efficient treatment regimen in this type of cancer [9]. Since the enhancement of protein levels is primarily correlated to the amplification of the corresponding gene c-erbB2, fluorescence in situ hybridization (FISH) has been established for the determination of Her-2/neu gene. FISH is characterized by excellent sensitivity (96.5\%) and specificity (100\%) [10]. Thus, this diagnostic assay has been introduced in routine clinical pathology, despite the considerable costs involving expensive reagents and the need to purchase high priced fluorescent equipment before deciding the further steps in the comparably much more expensive treatment with all its possible therapeutic side effects.

For this reason, the use of small monochromatic LED modules as the required light source for routinely per- formed FISH analysis of Her-2/neu status appeared to us as a promising alternative to eventually replace the shortlived and expensive conventional mercury vapor lamp. For this purpose, a commercially available AFTER (Amplified Fluorescence by transmitted Excitation of Radiation) LED Fluorescence Microscope Kit (Lab Vision, Fremont, USA) was mounted to a standard Zeiss Axiostar Plus transmitted light microscope (Medac, Wedel, Germany), providing a simple adaptation of a fluorescence microscope. Determination of ZyGreen c-erb-B2 gene was performed by attaching a $480 \mathrm{~nm}$ Fraen fluorescence light cassette to the Axiostar Plus in combination with a LP $510 \mathrm{~nm}$ long pass filter. For comparison reasons, the Zeiss microscope was also fitted with a Quicam FAST CCD digital camera, which is normally attached to the Nikon Eclipse 80i fluorescence microscope for routine determination of cerb-B2 gene amplification. Her-2/neu gene expression was documented at $400 \times$ magnification. A total of 30 tissue samples from patients with primary invasive breast carcinoma were analyzed by FISH. After mastectomy, the specimens were fixed by formalin and subsequently paraffin-embedded. Optimal comparability among all samples was achieved by producing a tissue micro array (TMA), as previously described [11]. FISH was performed, using ZytoLight Spec Her-2 Color Probe (ZytoVision GmbH, Bremerhaven, Germany). Briefly, a $4 \mu \mathrm{m}$ thick section of the TMA was deparaffinized with xylene, dehydrated and pre-treated with enzyme and heat, according to the manufacturer's instructions. After addition of $10 \mu \mathrm{l}$ SPEC HER2 Color probe, denaturation was carried out at $75^{\circ} \mathrm{C}$ for $10 \mathrm{~min}$, followed by hybridization overnight at $37^{\circ} \mathrm{C}$. Post hybridization washing, subsequent dehydration in ethanol and counterstaining with DAPI (4,6-diaminido2-phenylindole dihydrochloride)/antifade-solution was performed, as specified. The slides were kept in the dark at $4{ }^{\circ} \mathrm{C}$ until evaluation.

The age of the patients ranged between 44 years and 84 years (median age $61 \mathrm{y}$ ) with $77 \%$ of the women being in the postmenopausal phase. The majority of the breast cancer tissues $(86 \%)$ were related histologically to the invasive ductal type of tumor. Amplification of cerb-B2 gene was detected by FISH in $36 \%$ of the specimens. Brightness of the Her-2/neu gene signals was always sufficient using the LED equipped Axiostar Plus microscope and corresponding photographs of high quality were captured by extended integration times between 3 and $10 \mathrm{sec}-$ onds.

To our knowledge, this is the first attempt to use LED modules instead of a $100 \mathrm{~W}$ mercury vapor lamp as light source to perform FISH analysis of clinically relevant Her2/neu gene expression for routine pathology. Up to date, the introduction of LED technology in diagnostic research has been very successful as recently demonstrated for the 

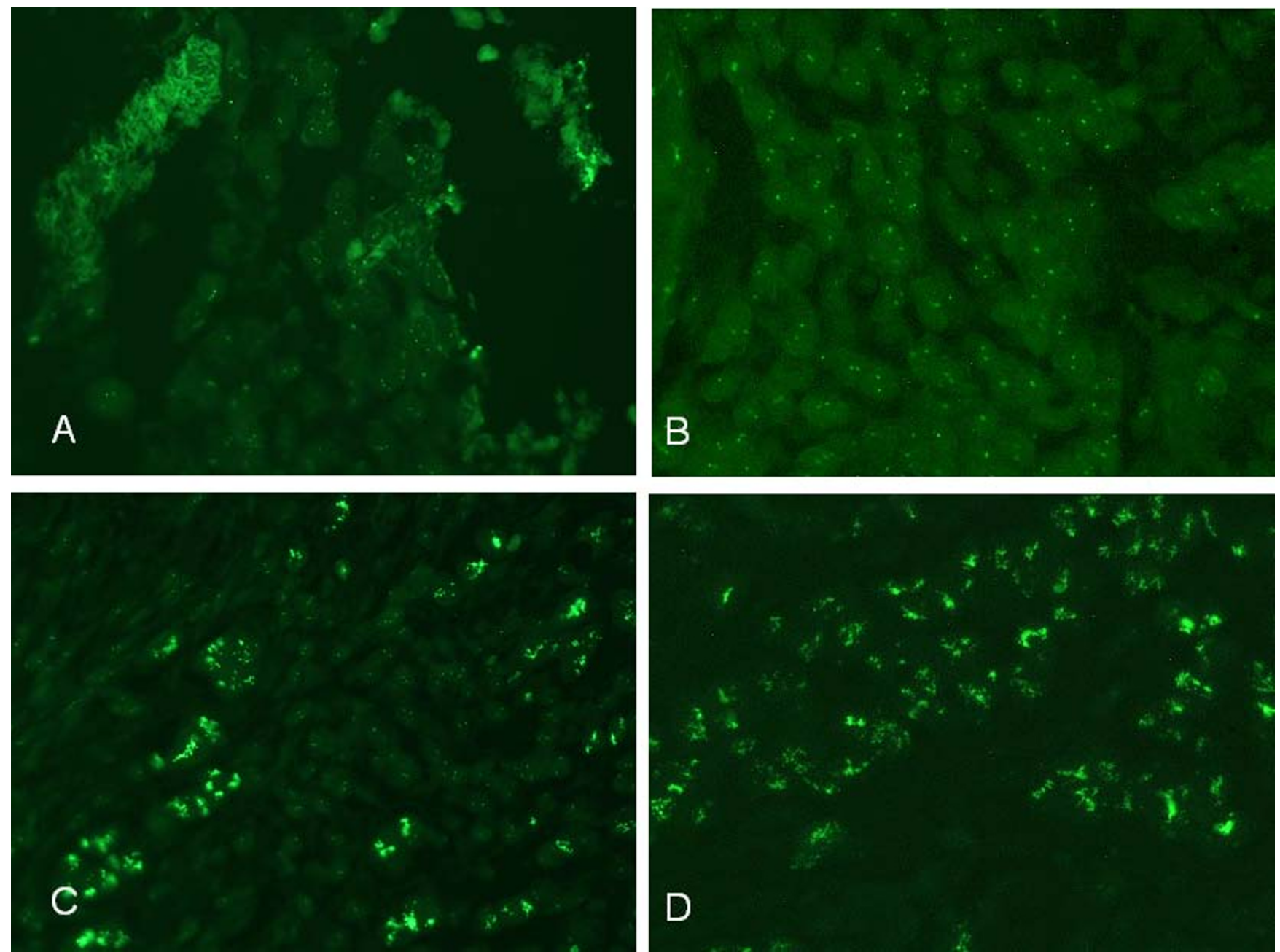

Figure I

Detection of Her-2/neu gene expression in human breast cancer tissue by FISH analysis. Two exemplary tissues of breast cancer exhibiting no amplification (A, B) or strong amplification of Her-2/neu gene (C, D) are shown (400x magnification). ZyGreen labeled Her-2/neu gene signals captured by advanced Nikon fluorescent microscope in combination with conventional 100W mercury vapor lamp $(\mathbf{A}, \mathbf{C})$ are directly compared with those captured by standard bright field Carl Zeiss Axiostar Plus microscope equipped with a Fraen AFTER LED Fluorescence Microscope Kit (B, D). Cerb-B2 gene expression was detected by a $480 \mathrm{~nm}$ Fluorescence light cassette combined with a $510 \mathrm{~nm}$ long pass emission filter mounted to the Axiostar microscope. Equal quality of the captured pictures was achieved by integration times between I and 3 seconds (A, C, I00W mercury vapor) and 6 and 10 seconds (B, D, LED).

fluorescence based screening of tuberculosis $[5,6,12]$. Likewise, in our studies the standard light transmission microscope Axiostar Plus became suitable for FISH analysis by simply attaching a commercially available adaptation kit for fluorescence microscopy. The appropriate combination of a particular LED module and the corresponding long pass emission filter was sufficient to replace the advanced Nikon fluorescence microscope. Moreover, the lack of heat production by the LED light sources completely avoided common safety problems related to conventional mercury vapor lamps. The extension of the integration time was the only major modifica- tion of the otherwise identical conditions to capture pictures of equal quality as compared to the routinely used high priced fluorescence equipment. Integration times less than 3 times shorter to be sufficient for documentation, as demonstrated for the $100 \mathrm{~W}$ mercury lamp, still emphasize the need for LED modules with further increased illumination power. Moreover, the development of LED light sources with corresponding long pass emission filters that are suitable for the detection of ZyOrange labeled probes would enable the combined analysis of both cerb-B2 gene and corresponding chromosome 17 as the most reliable determination of the Her-2/neu status 
in patients with breast cancer. In addition, the possibility to simply switch between different LED modules instead of the necessity to exchange the whole elements would considerably simplify the applicability of LED elements, since fluorescence based assays such as FISH using commercially available dual color labeled kits are increasingly introduced into clinical research. In summary, although there is still need for some further developments, our own experiences emphasize the high potential of these monochromatic LED elements with all their characteristic features to provide a serious alternative to conventional advanced fluorescence microscopy in routine pathology. Without dispute this low-cost technology has initiated a sustainable technological progress giving direction also to the growing field of molecular pathology.

\section{Competing interests}

The authors declare that they have no competing interests.

\section{Authors' contributions}

DSL carried out the FISH analyses and drafted the manuscript. TZ was responsible for the surgical part and clinical data. PZ provided the technological capabilities. HS and EV were responsible for the histopathological aspects. TG conceived of the study and was involved in drafting the manuscript. All authors have read and approved the final manuscript.

\section{Acknowledgements}

The authors like to thank Dr. N. Stumpp from MEDAC for providing the VIS LED cassettes and long pass filters for testings as well as Maria Lammers and Jasmin Tiebach for excellent technical support.

\section{References}

I. Lachmeyer R, Götz M, Kleinkes M, Pohlmann W: LED-Technik im Scheinwerfer - neue Möglichkeiten mit Leuchtdioden. ATZ I08 2006, I I:956-96I.

2. Eichhorn K, Götz M, Himmler A, Roslak J: Aktives Licht - innovative Ansätze für die nächste Scheinwerfergeneration. ATZ I07 2005, II:

3. World's Highest brightness of $\mathbf{9 0 0} \mathbf{~ I m}$ at $\mathbf{1 0}$-Watt Seoul Semiconductor's News 2008 [http://www.seoulsemicon.com/en/prCenter/ news/view.asp?seq $=45]$.

4. Connally R, Piper J: Solid-state time-gated luminescence microscope with ultraviolet light-emitting diode excitation and electron-multiplying charge-coupled device detection. J Biomed Opt 2008, 13:034022.

5. Hänscheid T: The future looks bright: low-cost fluorescent microscopes for detection of Mycobacterium tuberculosis and Coccidiae. Trans R Soc trop Hyg 2008, 102:520-I.

6. Van Deun A, Chonde TM, Gumusboga M, Rienthong S: Performance and acceptability of the FluoLED Easytrade mark module for tuberculosis fluorescence microscopy. Int J Tuberc Lung Dis 2008, 12:1009-14.

7. Vogel CL, Cobleigh MA, Tripathy D, Gutheil JC, Harris LN, Fehrenbacher L, Slamon DJ, Murphy M, Novotny WF, Burchmore M, Shak S, Stewart SJ, Press M: Efficacy and safety of trastuzumab as a single agent in first-line treatment of Her2-overexpressing metastatic breast cancer. J Clin Oncol 2002, 20:719-26.

8. McKeage K, Perry CM: Trastuzumab: a review of its use in the treatment of metastatic breast cancer overexpressing HER2. Drugs 2002, 62:209-43.
9. Baselga J: Herceptin alone or in combination with chemotherapy in the treatment of Her-2 - positive metastatic breast cancer: pivotal trials. Oncology 200I, 61:14-2I.

10. Pauletti G, Godolphin W, Press M, Slamon DJ: Detection and quantitation of Her-2/neu gene amplification in human breast cancer archival material using fluorescence in situ hybridization. Oncogene 1996, 13:63-72.

II. Goldmann T, Drömann D, Marzouki M, Schimmel U, Debel K, Branscheid D, Zeiser T, Rupp J, Gerdes J, Zabel P, Vollmer E: Tissue microarrays from HOPE-fixed specimens allow for enhanced high throughput molecular analyses in paraffinembedded material. Pathol Res Pract 2005, 201 :599-602.

12. Anthony RM, Kolk AH, Kuijper S, Klatser PR: Light emitting diodes for auramine $O$ fluorescence microscopic screening of Mycobacterium tuberculosis. Int J Tuberc Lung Dis 2006, I0(9): 1060-1062.
Publish with Biomed Central and every scientist can read your work free of charge

"BioMed Central will be the most significant development for disseminating the results of biomedical research in our lifetime. "

Sir Paul Nurse, Cancer Research UK

Your research papers will be:

- available free of charge to the entire biomedical community

- peer reviewed and published immediately upon acceptance

- cited in PubMed and archived on PubMed Central

- yours - you keep the copyright

Submit your manuscript here:

http://www.biomedcentral.com/info/publishing_adv.asp
BioMedcentral 